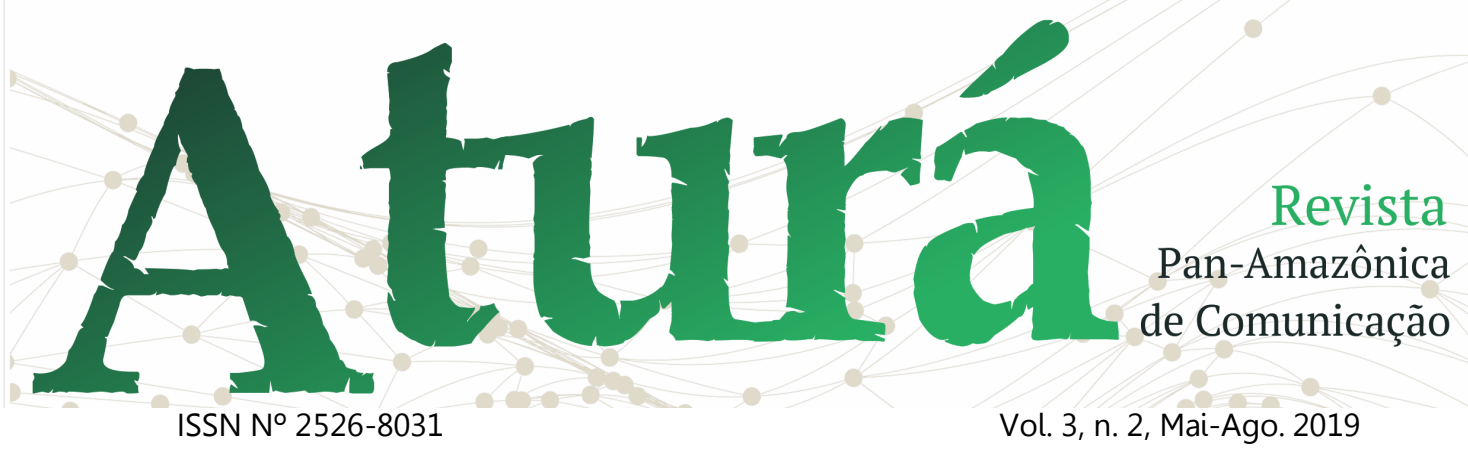

\title{
ENTRE O DOCUMENTÁRIO E O TELEJORNALISMO: a produção audiovisual de não-ficção da realizadora Simone Norberto
}

Between documentary and television news: Simone Norberto's non-fiction audiovisual production

Entre el documental y el telediario: la producción audiovisual de no ficción de la realizadora Simone Norberto

\author{
Juliano José de Araújo ${ }^{1}$ \\ Ingridy Carolliny Baldez dos Santos ${ }^{2}$
}

\section{RESUMO}

Este artigo apresenta uma análise dos documentários Forte Príncipe da Beira (1999), Expedição Trans-Jeri (2002) e Bizarrus (2010), todos da realizadora Simone Norberto, de Rondônia. Adota a análise fílmica como método. Discute as condições de realização desses filmes, as escolhas estéticas da realizadora e os assuntos priorizados pelas narrativas. Conclui-se que a produção audiovisual de não-ficção da realizadora Simone Norberto se situa na interseção entre os campos do documentário e do telejornalismo, tendo em vista suas características estéticas, como também a estrutura institucional que tornou possível a realização de seus filmes.

PALAVRAS-CHAVE: Cineasta rondoniense; Documentário; Telejornalismo; Rondônia.

\footnotetext{
${ }^{1}$ Doutor em Multimeios pela Universidade Estadual de Campinas (Unicamp), tendo realizado estágio de doutorado na Université Paris Ouest Nanterre La Défense (Paris X-Nanterre). É mestre em Comunicação pela Universidade Estadual Paulista (Unesp) e graduado em Comunicação Social/Jornalismo também pela Unesp. É professor adjunto do Departamento de Comunicação Social/Jornalismo do Campus de Vilhena da Universidade Federal de Rondônia (Unir). E-mail: araujojuliano@gmail.com.

${ }^{2}$ Estudante do curso de graduação em Jornalismo do Campus de Vilhena da Universidade Federal de Rondônia (UNIR) e bolsista do Programa para Iniciação Científica da Fundação de Amparo ao Desenvolvimento das Ações Científicas e Tecnológicas e à Pesquisa do Estado de Rondônia (FAPERO). E-mail: ingridybaldez@gmail.com.
} 


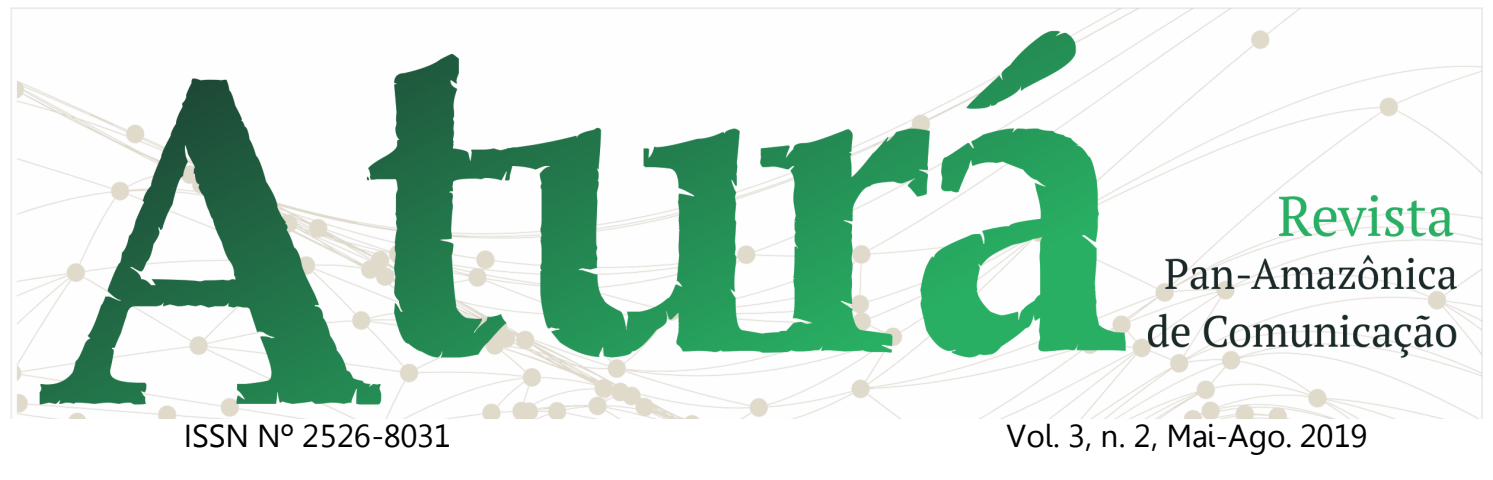

\section{ABSTRACT}

This paper analyzes the documentaries Forte Príncipe da Beira (1999), Expedição (2002), and Bizarrus (2010), all produced by Simone Norberto, filmmaker from Rondônia. By adopting the method of filmic analysis, this study discusses the conditions of production, the aesthetic choices by Norberto and the main topics addressed in these narratives. The aesthetic elements and the institutional structure that made Norberto's non-fiction audiovisual production possible lead us to the conclusion that her work can be situated in the intersection of documentary and television news.

KEYWORDS: Filmmaker from Rondônia; Documentary; Broadcast journalism; Rondônia.

\section{RESUMEN}

Este artículo presenta un análisis de los documentales Forte Príncipe da Beira (1999), Expedição Trans-Jeri (2002) e Bizarrus (2010), todos de la realizadora Simone Norberto, de Rondonia. Adopta el análisis fílmico como método. Discute las condiciones de realización de las películas, las opciones estéticas de la realizadora y los asuntos prioritarios de las narrativas. Se concluye que la producción audiovisual de no ficción de la realizadora Simone Norberto se sitúa en la intersección entre los campos del documental y del telediario, teniendo en vista sus características estéticas, así como también la estructura institucional que ha hecho posible la realización de sus películas.

PALABRAS CLAVE: Cineasta rondoniense; Documental; Telediario; Rondonia.

Recebido em: 21.02.2019. Aceito em: 24.04.2019. Publicado em: 01.05.2019. 


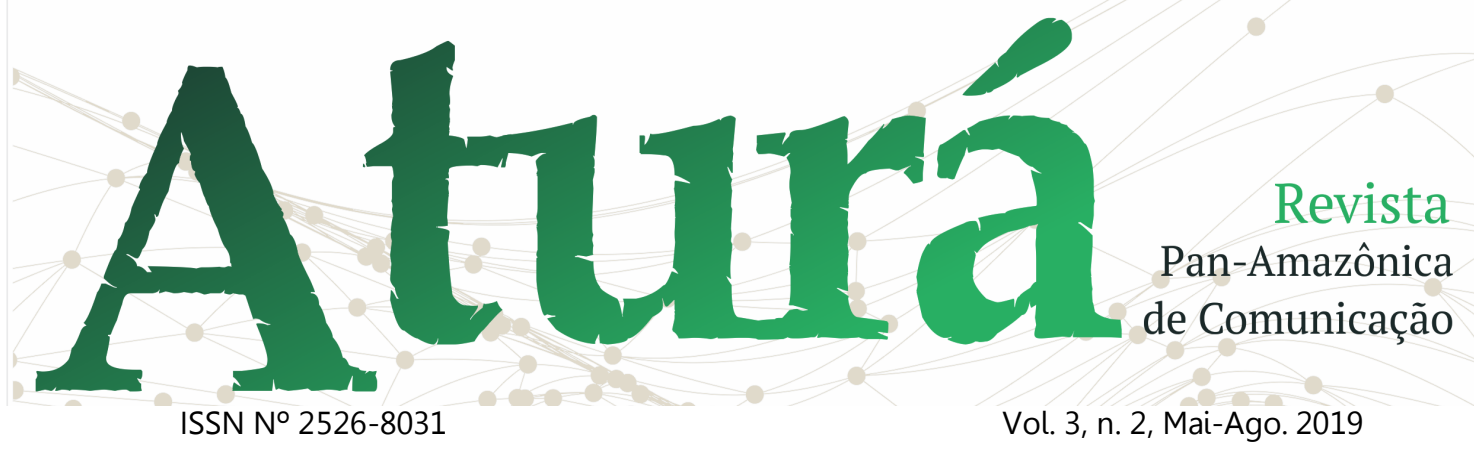

\section{Introdução}

Este artigo apresenta uma análise dos documentários Forte Príncipe da Beira (1999), Expedição Trans-Jeri (2002) e Bizarrus (2010), todos da realizadora Simone Norberto. São os resultados preliminares do projeto de pesquisa "Práticas e imagens documentais na cultura audiovisual da Amazônia Ocidental $^{3 "}$, que consiste em um estudo da produção audiovisual de não-ficção dos realizadores ${ }^{4}$ de Rondônia.

Nossa problemática consistiu no estudo da produção audiovisual de nãoficção da realizadora Simone Norberto para conhecer as práticas e imagens documentais presentes nos seus documentários. Procuramos investigar os procedimentos de criação, os métodos de trabalho e as condições de realização dos documentários dessa realizadora, identificando também as influências estéticas e as temáticas priorizadas por suas narrativas.

\footnotetext{
3 Projeto aprovado na Chamada Universal $n^{\circ}$ 003/2015 da Fundação de Amparo ao Desenvolvimento das Ações Científicas e Tecnológicas e à Pesquisa do Estado de Rondônia (FAPERO).

${ }^{4}$ Além da produção audiovisual de não-ficção da realizadora Simone Norberto, integram o corpus do projeto de pesquisa documentários dos seguintes realizadores: Alexis Bastos, Beto Bertagna, Carlos Levy, do casal Fernanda Kopanakis e Jurandir Costa, Joesér Alvarez e do casal Lídio Sohn e Pilar de Zayas de Bernanos.
}

Adotamos como metodologia a análise fílmica (AUMONT e MARIE, 2009; PENAFRIA, 2009) para o estudo dos três documentários de nosso corpus, em uma perspectiva textual e contextual, isto é, estabelecendo um diálogo entre elementos internos (imagem, som etc.) e externos (entrevista com a realizadora) dos documentários.

A análise está estruturada da seguinte forma: inicialmente, traremos um breve perfil biofilmográfico da realizadora Simone Norberto; em seguida, discorreremos sobre o conceito de documentário a partir do pensamento de Bill Nichols, apresentando também os diferentes modos de documentário; por fim, faremos o estudo dos documentários Forte Príncipe da Beira, Expedição TransJeri e Bizarrus. Além de Nichols, dialogaremos também com Gustavo Souza (2009), Sílvio Da-Rin (2008) e uma entrevista que fizemos com a realizadora (NORBERTO, 2017).

\section{Perfil biofilmográfico da realizadora Simone Norberto \\ Simone Norberto nasceu em São} Paulo em 1973, tendo chegado em Rondônia em 1976, com três anos e meio de idade. Ela explica que sua família veio para o estado de Rondônia a trabalho no contexto dos fluxos migratórios. Inicialmente, seu pai atuou em uma 


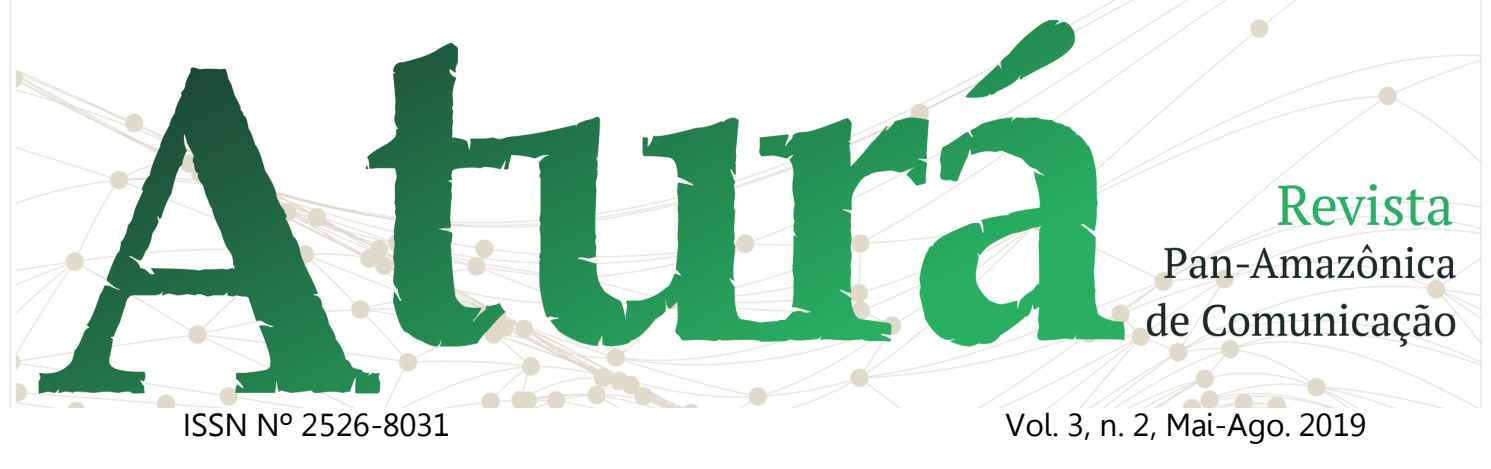

fazenda e depois em uma firma de topografia que prestava serviços para o Instituto Nacional de Colonização e Reforma Agrária. Já sua mãe era dona de casa, cuidando de quatros filhos: dela, das filhas gêmeas e de seu irmão. (NORBERTO, 2017)

A realizadora afirma que pôde conhecer duas Rondônias, a da capital e a do interior, pois, dos quatro aos 17 anos morou em várias cidades do interior, como Vilhena, Espigão do Oeste, Pimenta Bueno e Cacoal, indo residir em Porto Velho, a capital de Rondônia, somente em 1995 após um período de estudos em São Paulo, onde fez duas graduações. (NORBERTO, 2017)

Sua formação situa-se no campo da Comunicação e de Letras. Em 1993, graduou-se em Jornalismo pela Faculdade de Comunicação Social Cásper Líbero e, em 1994, em Letras pela Universidade de São Paulo. Ela comenta em entrevista que esse período foi muito rico para sua formação audiovisual:

Quando fui pra São Paulo pra fazer faculdade aí o universo se abriu, porque era aquela limitação, né? Aí, eu ia no cinema quase todos os dias, queria tirar o atraso, né? Tudo que eu não tinha assistido vivendo aqui em Rondônia, eu tentei assistir lá (NORBERTO, 2017).

Após se formar, retornou para Rondônia, tendo atuado durante 14 anos, como repórter, apresentadora e editora na Rede Amazônica de Televisão, emissora de TV afiliada da Rede Globo em Porto Velho. É também cineclubista estando à frente do Cine Oca, um cineclube que é referência em Rondônia e foi fundado em 2005, e desde 2014 é responsável em Porto Velho pela realização da Mostra de Cinema e Direitos Humanos.

Especializou-se em Jornalismo e Mídia em 2004 pela Faculdade Interamericana de Porto Velho, onde foi docente. Também lecionou no curso de Comunicação da Faculdade de Ciências Humanas, Exatas e Letras de Rondônia. Atualmente, é jornalista do Tribunal de Justiça de Rondônia, atuando em sua Coordenadoria de Comunicação.

Dentre os principais trabalhos audiovisuais de não-ficção da realizadora Simone Norberto, podemos citar: Forte Príncipe da Beira (1999), Cacau - A Semente dos Deuses (2000), Expedição Trans-Jeri (2002), Aventura no Vale do Apertado (2004), Aventura nas Corredeiras de Machadinho (2005), Irerua - Festa Parintintim (2007), Missão Rondon (2007), Terreiros (2007), Saída para o Pacífico (2009) e Bizarrus (2010).

Fez também os filmes Repositório (2003) e Curso (2006), ambos classificados como experimentais pela cineasta, e finalizou seu último documentário em 2018, Nazaré Encantada (2018), filme sobre os mitos e as lendas ribeirinhas da região do Baixo Rio Madeira, 


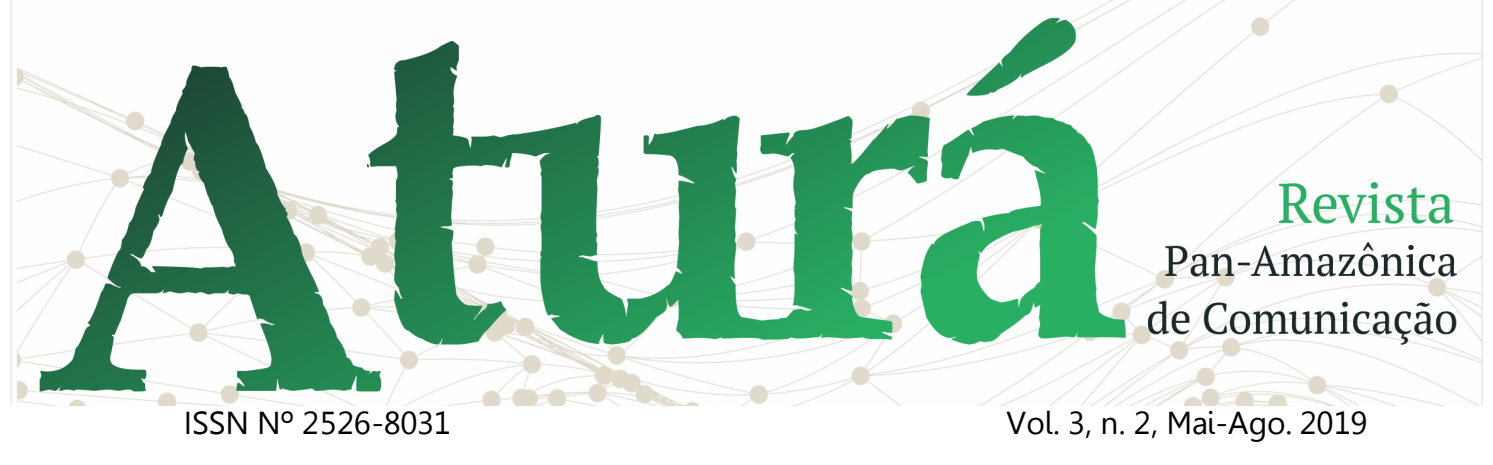

notadamente a comunidade de Nazaré, em Porto Velho, tema de sua dissertação de mestrado (NORBERTO, 2016).

\section{Análise fílmica dos documentários}

\section{A realizadora Simone Norberto (2017) afirma em entrevista que o documentário constitui-se como um espaço para se aprofundar mais nas temáticas, buscar novas fontes, novas perspectivas, visões de mundo, um recorte maior sobre determinado assunto etc., tendo em vista que, como ela destaca, nem sempre é possível fazer isso no dia a dia da reportagem para} televisão. Diz ainda que:

(...) eu acredito na profissão, com bastante engajamento, sabe? A gente tem um papel na sociedade de transformação, tem que trazer alguma coisa de reflexão e o documentário é um pouco isso, você tentar mostrar a sociedade de uma forma mais crítica (NORBERTO, 2017).

Esse ponto de vista de Simone sobre o conceito de documentário vai ao encontro do pensamento de Bill Nichols, presente no livro Introdução ao documentário. Segundo o autor:

Em geral, portanto, o documentário testemunha a perspectiva distinta, às vezes incomum, da qual os cineastas veem aspectos do mundo que compartilhamos. Os documentários organizam-se para nos convencer, persuadir ou predispor a uma determinada visão do mundo que temos em comum. O trabalho do documentário não recorre exclusivamente a nossa sensibilidade estética: ele pode divertir ou agradar, mas o faz como esforço retórico

ou persuasivo dirigido ao mundo social existente. O documentário não só ativa nossa percepção estética (ao contrário de um filme estritamente informativo ou instrutivo), ativa também nossa consciência social (NICHOLS, 2016, p.118).

Tendo em vista essa perspectiva de crítica social, Nichols define em sua argumentação o documentário como um filme de representação social. Para o teórico:

O vínculo entre o documentário e o mundo histórico é forte e profundo. $\mathrm{O}$ documentário acrescenta uma nova dimensão à memória popular e à história social. O documentário se engaja no mundo pela representação (NICHOLS, 2016, p.61).

Nichols, principal autor utilizado durante nossa pesquisa, propõe seis modos, categorias ou estilos de representação da realidade no documentário: o modo poético, o modo expositivo, o modo observativo, o modo participativo, o modo reflexivo e o modo performático (NICHOLS, 2016). Faremos, agora, uma breve conceituação de cada um desses modos para apresentarmos, em seguida, a análise de nosso corpus.

O modo poético consiste em representar a realidade através da fragmentação, não tendo uma preocupação com a montagem, a localização no tempo ou espaço e tampouco não apresentando de forma aprofundada os atores sociais. Este modo evidencia notadamente a subjetividade e 


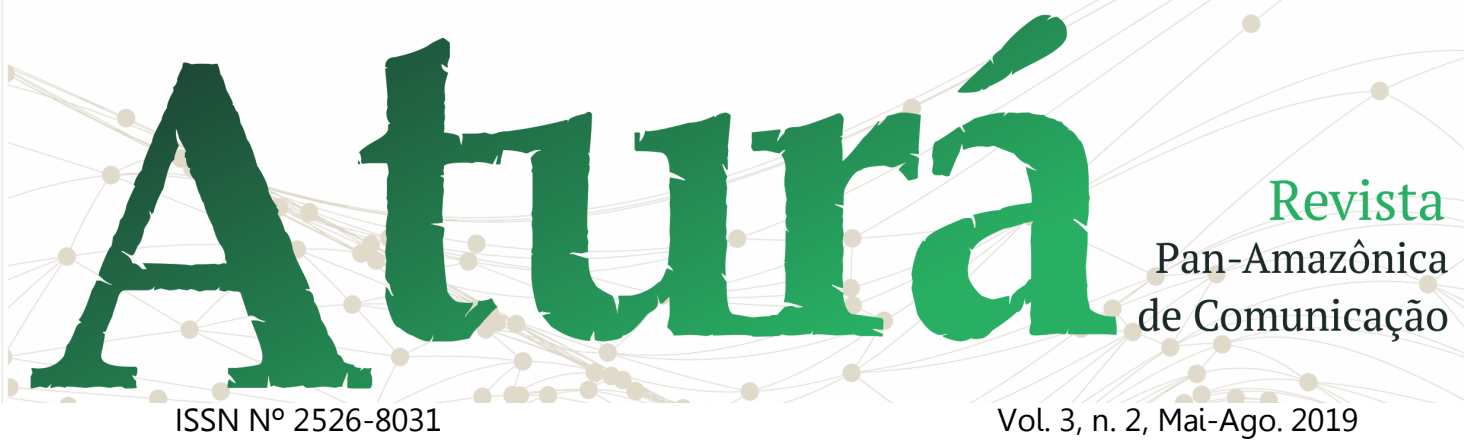

se preocupa com a estética. Em relação à construção do texto, podemos encontrar o uso de poemas e trechos de obras literárias.

Ao contrário do modo poético, o modo expositivo preocupa-se mais com a defesa de argumentos do que com a estética e a subjetividade. Sua característica predominante é a objetividade. Este modo preocupa-se em narrar um fato de maneira a manter a continuidade da argumentação. Dirige-se ao espectador diretamente, expondo um argumento ou contando uma história. Outra característica importante neste modo é o uso do comentário em voz over, também chamado de "voz de Deus", narração que se assemelha à empregada nos noticiários televisivos.

Já no modo observativo o documentarista busca captar a realidade tal como aconteceu, mostrando a observação espontânea da experiência vivida. São filmes sem trilha sonora, sem comentário em voz over e, muitas vezes, até sem entrevista. Os atores sociais agem como se o cineasta não estive ali ou, melhor, fosse uma "mosca na parede", fazendo com que o espectador tire suas conclusões baseadas no que foi observado.

O modo participativo coloca o cineasta no filme, juntamente com sua equipe. Assim, ele se torna um sujeito ativo no processo de realização cinematográfica, incluindo-se como ator social. Trata-se de um aspecto que é deixado claro para o espectador. A entrevista constitui-se como uma das estratégias fílmicas mais comuns de encontro entre cineasta e personagem no estilo participativo.

Já o modo reflexivo procura estimular no espectador uma consciência crítica sobre sua relação com o documentário e aquilo que é representado em imagens e sons, questionando, assim, os procedimentos de realização audiovisual. Mostra as consequências da produção tanto para os atores sociais, criador e público.

Por fim, o modo performático utiliza, de certa forma, de um estilo de criação livre. Tanto é que pertencem a esse modo os filmes de vídeo-arte, de cinema experimental e de vanguarda. Caracteriza-se principalmente por licenças poéticas, estruturas narrativas menos convencionais e formas de representação mais subjetivas, combinando o real e o imaginário, questões de memória e de identidade, de acordo com seu realizador. São documentários também que se apresentam, às vezes, como autobiográficos ou ligados às subjetividades de grupos subrepresentados, como mulheres, negros, gays e lésbicas. 


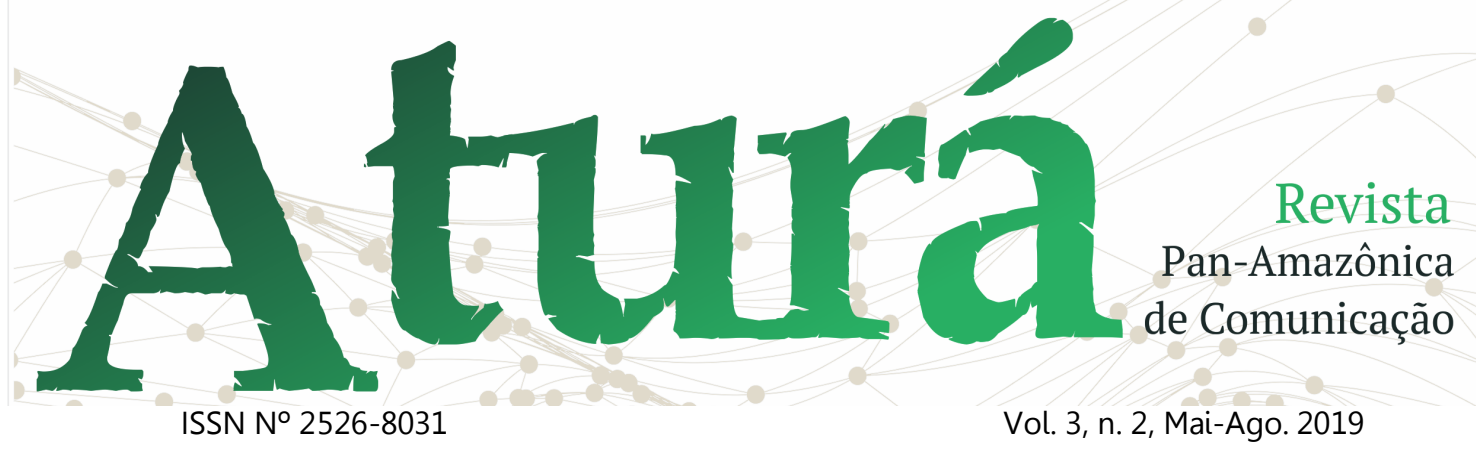

É importante destacarmos que Nichols (2016) deixa claro que a identificação de um filme com um certo modo não precisa ser total. As características de um modo funcionam como dominantes em um dado filme, que the dão maior estrutura, mas não limitam ou determinam todos seus aspectos de criação. Sendo assim, o autor esclarece que:

Esses modos determinam uma estrutura de afiliação frouxa, dentro da qual os indivíduos podem trabalhar. Eles estabelecem as convenções que um determinado filme talvez adote e oferecem expectativas específicas que os espectadores esperam ver satisfeitas. Cada modo compreende exemplos que podemos identificar como protótipos ou modelos: esses protótipos parecem expressar de maneira exemplar as características mais peculiares de cada modo. Um protótipo não pode ser copiado literalmente, mas pode ser emulado quando outros cineastas, com outras vozes, tentam representar aspectos do mundo histórico usando um protótipo que modulam com seus próprios pontos de vista distintos (NICHOLS, 2016, p. 166167).

Julgamos que essa breve retomada do pensamento de Nichols foi necessária para podermos entender o conceito de documentário, sua importância no contexto do audiovisual e, em especial, os diferentes modos, tendo em vista que a produção audiovisual de não-ficção da realizadora Simone Norberto revela o emprego de técnicas de diferentes estilos, além de utilizar também recursos característicos do formato jornalístico para televisão. Analisemos, agora, de forma mais detida, os documentários Forte Príncipe da Beira, Expedição TransJeri e Bizarrus.

Forte Príncipe da Beira é o primeiro documentário de Simone, realizado em 1999 para o canal Amazon Sat ${ }^{5}$, da Rede Amazônica de Televisão. O filme busca narrar a aventura estrangeira na Amazônia, tendo como foco o monumento levantado pelos portugueses em 1776 - o Forte Príncipe da Beira que dá nome ao filme - às margens do Rio Guaporé, em Costa Marques, interior de Rondônia, para defender a fronteira do Brasil dos espanhóis em um contexto de uma política expansionista do século XVIII.

O documentário divide-se, basicamente, em três grandes blocos. $\mathrm{O}$ primeiro é dedicado a apresentar a

${ }^{5}$ O Amazon Sat tem como slogan "A cara e a voz da Amazônia e do amazônida". Sua proposta é: "O Amazon Sat surgiu para suprir a vontade de falar sobre a Amazônia de uma maneira diferenciada, falar da região para a própria região e seu povo, mostrar o olhar de quem melhor vive essa realidade tão peculiar e tão intensa. Dessa forma o canal divulga as riquezas, a cultura, a tradição e a história da Amazônia e de seu povo. Com a proposta de ser a cara e a voz da Amazônia e do amazônida, o Amazon Sat constrói diariamente um conteúdo pautado exclusivamente nessa temática, pois busca promover a integração de todos os estados da região (Acre, Amapá, Amazonas, Pará, Rondônia, Roraima, Tocantins, Maranhão e Mato Grosso)." Disponível em http://www.amazonsat.com.br/quem-somos/ 


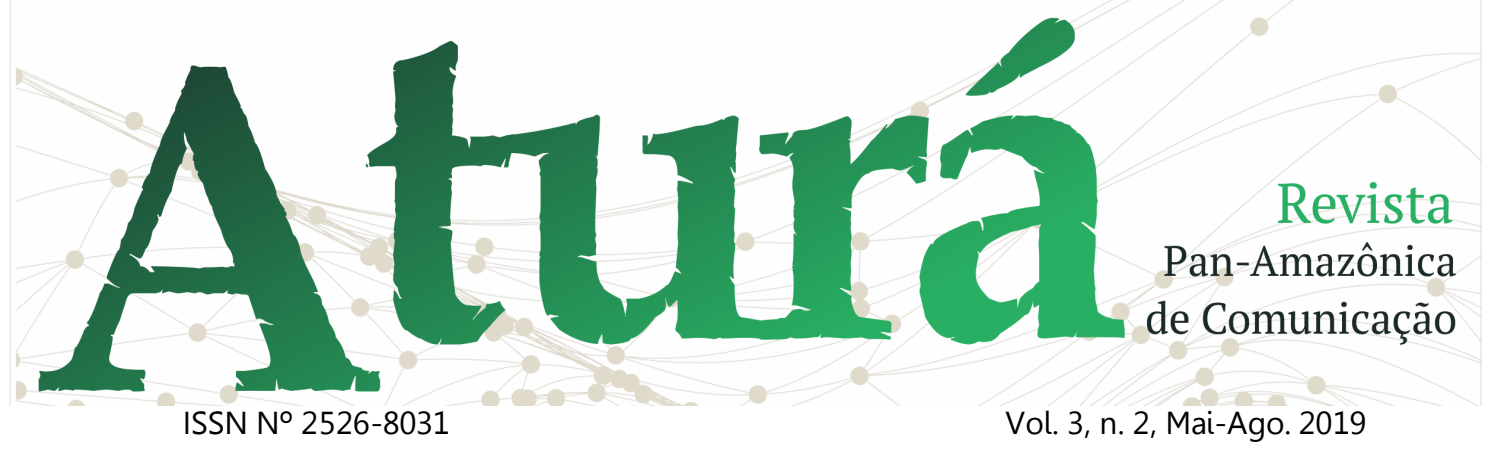

história do Forte Príncipe da Beira, notadamente os motivos que levaram Portugal a construí-lo e as principais figuras políticas envolvidas. Já o segundo bloco trata especificamente da construção do Forte, considerada como um projeto moderno de engenharia para a época. Por fim, o terceiro bloco mostra o abandono por que passou, devido ao esgotamento das minas da capitânia de Mato Grosso, e sua redescoberta no início do século $X X$, problematizando também o desmazelo com o local por parte do governo no cenário atual, juntamente com a falta de turismo em um lugar com tamanho potencial.

Para tanto, Simone Norberto emprega como principal estratégia fílmica o comentário em voz over com imagens em estilo observativo do Forte Príncipe da Beira e um farto material de arquivo (documentos históricos como mapas, pinturas, retratos dos personagens políticos do período envolvidos com a construção etc.). Há também algumas entrevistas com pessoas que visitam 0 Forte e contam suas impressões sobre o local, além de alguns especialistas, como o historiador Mathias Mendes, para maior aprofundamento da temática regional abordada.

É importante pontuarmos que o comentário em voz over utilizado pela realizadora assume no documentário duas perspectivas, oscilando entre a poesia e o didatismo. No primeiro caso, Simone diz que sempre que possível emprega a questão literária em suas produções, até mesmo por sua formação em Letras (NORBERTO, 2017). Já o tom didático do comentário é típico do modo expositivo de documentário, na perspectiva definida por Nichols (2016), frequentemente encontrado nos noticiários televisivos e dependente de uma lógica informativa transmitida para o espectador verbalmente.

Forte Príncipe da Beira destaca-se por sua trilha sonora com uma música composta especialmente para o documentário pelo músico regional Zezinho Maranhão 6 . Nessa perspectiva, podemos indicar a importância que 0 material sonoro tem para o filme, notadamente ao ser combinado com o texto poético do comentário.

O documentário foi originalmente veiculado no programa Amazônia Verdade, o qual lembra muito o formato de programas da Rede Globo, como Globo Repórter, e também os do canal National Geographic, voltado para apresentação de filmes, séries e programas de caráter educativo, abordando temas de ciência, história, meio ambiente etc.

\footnotetext{
6 Músico e compositor José Alves da Silva, o Zezinho Maranhão, foi um destacado artista de Rondônia. Faleceu em 7 de dezembro de 2013.
} 


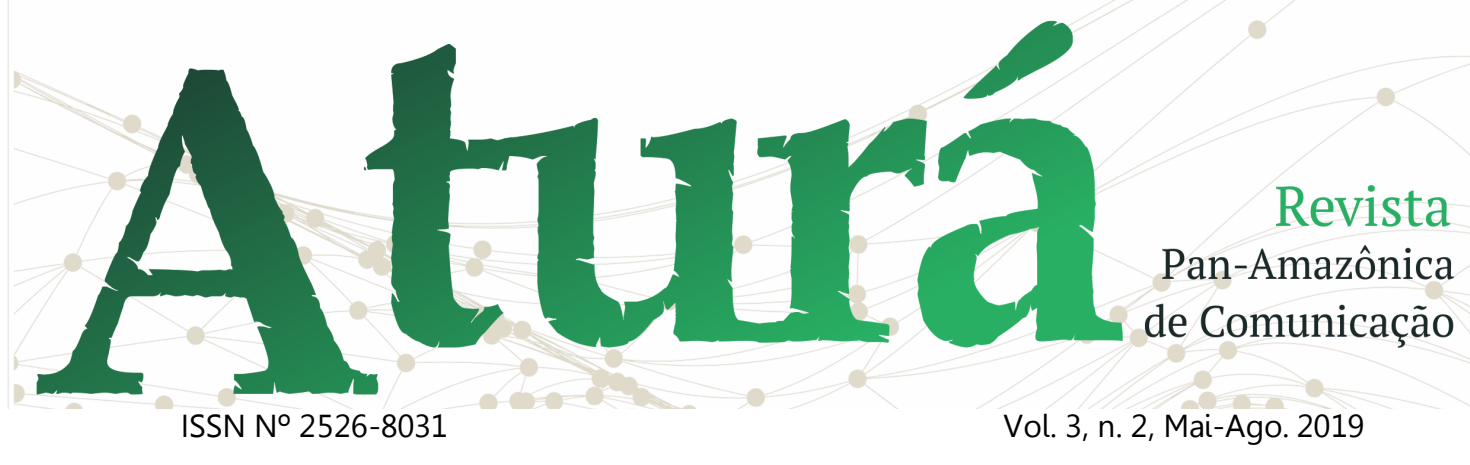

A esse respeito, é interessante indicar que a realizadora diz que sempre gostou, desde os tempos de sua graduação em Jornalismo, da produção audiovisual da National Geographic. Outra influência citada por ela são os documentários do cineasta Adrian Cowell, notadamente a série $A$ década da destruição, que traz um conjunto de imagens filmadas durante as décadas de 1980 e 1990, no qual a região amazônica passou por transformações significativas ${ }^{7}$. (NORBERTO, 2017)

Simone Norberto explica que o canal Amazon Sat, que tinha sido criado em 1997, estava, na época, precisando de

\footnotetext{
7 Segundo o site Histórias da Amazônia: 50 anos de memória audiovisual, da Pontífica Universidade Católica de Goiás, Adrian Cowell e Vicente Rios filmaram de janeiro de 1980 a setembro 1990 "ininterruptamente todo o processo do que viria a ser a série $A$ Década da Destruição, produzida para a Central Television de Londres em coprodução com a Universidade Católica de Goiás. Os temas dessa série incluem o primeiro contato com a tribo de índios isolados Uru-Eu-Wau-Wau, garimpeiros e madeireiros; a colonização e o desmatamento de Rondônia a partir da pavimentação da estrada BR-364, a campanha dos ambientalistas contra o financiamento do Projeto Polonoroeste pelo Banco Mundial; os grandes projetos Carajás e Tucuruí; o saque da floresta pelos garimpeiros; as primeiras tentativas de controlar os incêndios da Amazônia usando tecnologia de satélite; a vida e assassinato do Chico Mendes e a criação das primeiras reservas extrativistas; a pesquisa do cientista Enéas Salati que provou que o desmatamento reduzirá as chuvas na Amazônia e no Centro-Oeste do Brasil." Disponível

em http://imagensamazonia.pucgoias.edu.br/acervo.h tml\#15
}

produções audiovisuais históricas sobre pontos turísticos da Amazônia. Considerando seu perfil propositivo de repórter no âmbito da emissora, ela acabou sendo indicada para a realização desse documentário (NORBERTO, 2017).

Passemos, agora, para a análise do documentário Trans-Jeri. Esse filme é sobre a aventura de um grupo de jipeiros que sai de Porto Velho, capital de Rondônia, e percorre cinco mil quilômetros em vinte e quatro dias, de leste à oeste, com destino à Jericoacoara, no litoral do Ceará. Dentre as várias rodovias pelas quais o grupo passa, destaca-se a BR 230, mais conhecida como rodovia Transamazônica, construída durante a Ditadura Militar.

O trajeto da viagem dos jipeiros, que passa por várias cidades dos estados do Amazonas, Pará, Maranhã, Piauí e, finalmente, o Ceará, determina a construção da narrativa, que é conduzida por um comentário da realizadora, belas imagens em estilo observativo da flora e da fauna das regiões Norte e Nordeste e entrevistas com os jipeiros.

No decorrer do documentário, a repórter também levanta pontos críticos, por exemplo, as condições das estradas que os jipeiros enfrentaram. Também mostra locais que não são popularmente conhecidos, buscando trazer informações sobre cada um. 


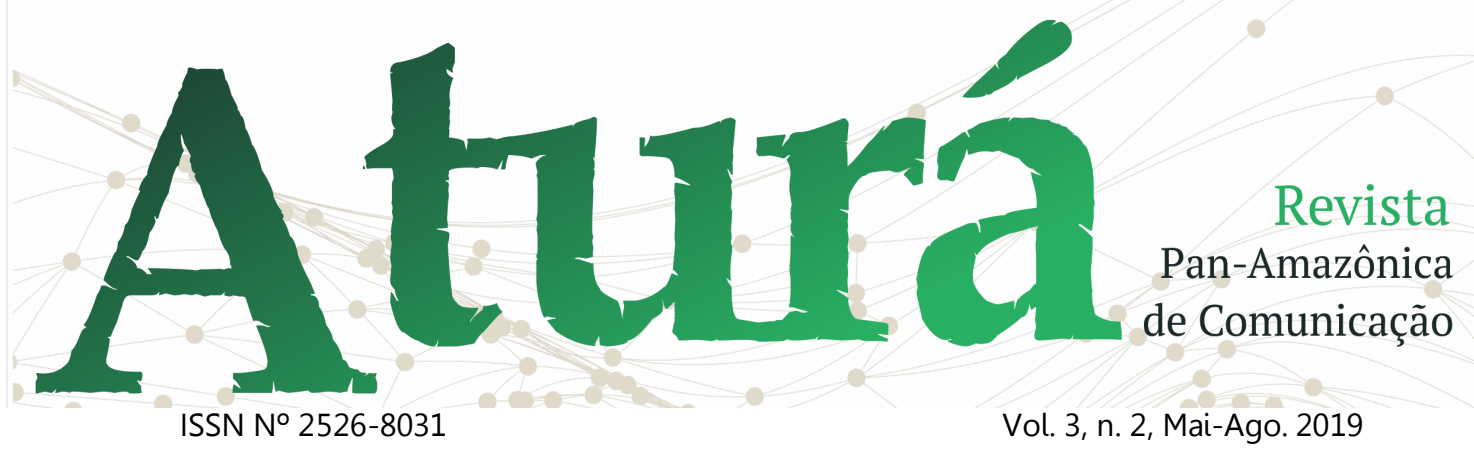

Algumas pessoas que são encontradas pelos jipeiros durante a viagem, como indígenas que moram às margens das rodovias, moradores dos municípios visitados etc., também são ouvidos em rápidas sonoras, tendo em vista a edição dinâmica do documentário, que também é marcado por uma trilha sonora em ritmo de aventura. A realizadora Simone Norberto também se faz presente em quadro em vários momentos por meio de passagens, um recurso típico do jornalismo para televisão.

Verificamos neste filme uma forte influência do campo telejornalístico, notadamente de um formato prédeterminado pela estrutura institucional da televisão. Isso explica-se, de certa forma, pela atuação da documentarista no âmbito da Rede Amazônica de Televisão. É importante apontarmos que muitos de seus documentários são desdobramentos de suas reportagens, possibilitando-lhe o tratamento de um assunto de forma mais aprofundada, como também de temas pouco pautados pela mídia local.

Nesse contexto, destacamos a importância do diálogo entre os campos do jornalismo e do documentário. Definido por uma linguagem préestabelecida e, notadamente, uma rotina de produção, o jornalismo muitas vezes não consegue transmitir o aprofundamento temático que $\mathrm{O}$ documentário tende a oferecer. A partir do pensamento de Gustavo Souza (2009), podemos compreender melhor essa questão:
(...) A produção da notícia se apoia em dois pilares: a cultura profissional do jornalista e a organização do trabalho e dos processos produtivos, ou, para utilizar o termo da teoria de comunicação, o newsmaking. Para Mauro Wolf, esses dois aspectos fornecem as condições necessárias para a noticiabilidade, que também é constituída pelo o que o autor considera com 'valor-notícia', ou seja, fatores que determinam os acontecimentos relevantes para serem transformados em notícia. A análise de tal processo deve privilegiar os meios em que as notícias são elaboradas e os seus produtores (SOUZA, 2007, p.163).

Com um caráter mais reflexivo, o documentário é uma forma mais ampla para o realizador tratar questões que, geralmente, foram veiculadas no campo jornalístico apenas em repercussões de notícias instantâneas, permitindo uma maior elaboração para que o tema seja retratado de forma aprofundada.

Podemos notar esta questão a partir do tempo de produção de um projeto audiovisual, pois o documentário não possui uma rotina de produção préestabelecida nos moldes do jornalismo; pelo contrário, o processo de realização de um documentário pode se estender durante meses e até anos, algo incompatível com a imposição do tempo 


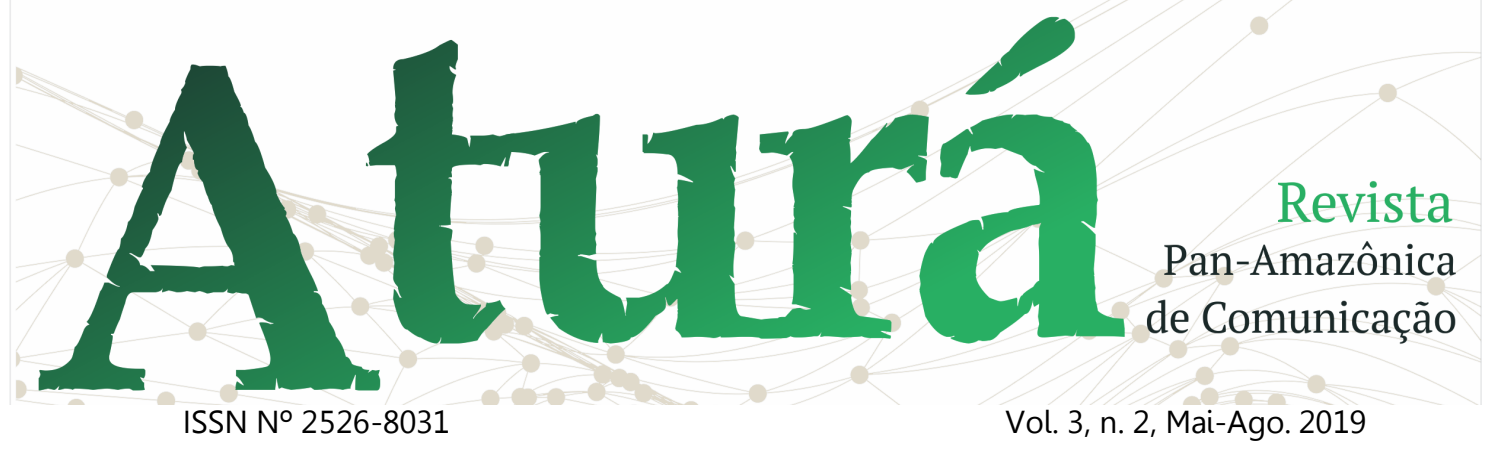

- o popular deadline - da cobertura jornalística factual.

Esse aprofundamento em uma determinada temática é oferecido pelo documentário por meio de suas inúmeras formas de desdobramentos - aqui, incluindo os diferentes modos ou estilos de documentários com suas várias estratégias narrativas disponíveis para 0 realizador, já discutidas por nós -, diferentemente da reportagem que deve seguir seu padrão jornalístico com o texto narrado em off, as entrevistas e a passagem do repórter.

No caso de Expedição Trans-Jeri, documentário analisado aqui, fica evidente esse peso do formato televisivo voltado, em certa medida, mais para o entretenimento do espectador com a aventura dos jipeiros, e não para o aprofundamento das questões econômicas, políticas e sociais que se relacionam à rodovia Transamazônica, e que não são, necessariamente, o foco do filme.

Tanto é que o documentário foi transmitido pela Rede Amazônica de Televisão no formato de um programa especial que lembra, em muitos momentos, o Globo Esporte ${ }^{8}$. Vale notar que Expedição Trans-Jeri foi realizado

\footnotetext{
8 Bill Nichols (2016, p.40) alerta-nos que uma estrutura institucional "impõe uma maneira institucional de ver e falar, que funciona como um conjunto de limites, ou convenções, tanto para o cineasta como para o público."
}

com financiamento próprio de Simone e de parceiros, como o Jeep Club de Porto Velho.

Sobre as condições de realização de seus filmes, Simone Norberto esclarece que não houve, da parte da emissora de televisão, um incentivo para as produções, na medida em que elas acabam sendo mais o resultado da proposição dos repórteres. (NORBERTO, 2017)

Avancemos para a análise de Bizarrus. Se Expedição Trans-Jeri apresenta, como argumentamos, uma forte influência do campo telejornalístico, e Forte Príncipe da Beira lembra programas como o Globo Repórter e da National Geographic, Bizarrus talvez se apresente como o documentário de caráter mais autoral dos três que estamos analisando.

O documentário Bizarrus retrata um projeto de ressocialização com base no teatro, desenvolvido no presídio Ênio Pinheiro, em Porto Velho, capital de Rondônia. Foi realizado por Simone no âmbito da Coordenadoria de Comunicação do Tribunal de Justiça de Rondônia.

Tendo em vista os modos de documentário propostos por Bill Nichols, podemos afirmar que esse filme se constitui em um documentário contemporâneo que revela diversidades estilísticas. Podemos identificar nele a 


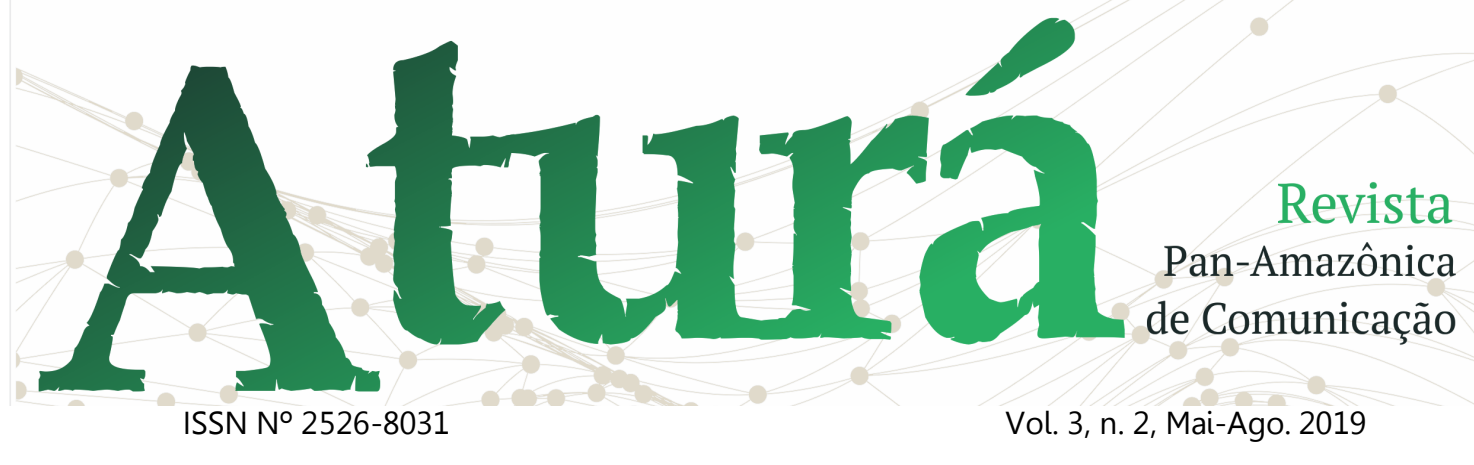

presença, em especial, dos modos observativo e participativo de documentário.

Nichols defende que o modo observativo acompanha a vida como ela é vivida, tendo traços do estilo jornalístico, como câmera tremida, sons captados no ambiente de filmagem e o acompanhamento dos atores sociais que interagem entre si, ignorando a presença das câmeras e dos cineastas.

Deste modo, o espectador assume um papel em que deve tirar suas próprias conclusões baseadas no que foi observado. De acordo com Nichols, com a ausência do cineasta é importante que o espectador determine de forma mais ativa o que está sendo abordado. Sílvio Da-Rin (2008) propõe que:

A expressão mais típica do modo observacional foi o cinema direto norteamericano, que procurou comunicar um sentido de acesso imediato ao mundo, situando o espectador na posição de observador ideal; defendeu radicalmente a não-intervenção; supriu o roteiro e minimizou a atuação do diretor durante a filmagem; desenvolveu métodos de trabalho que transmitiam a impressão de invisibilidade da equipe técnica; renunciou a qualquer forma de 'controle' sobre os eventos que se passavam diante da câmera; privilegiou o plano-sequência com imagem e som em sincronismo; adotou uma montagem que enfatizava a duração da observação; evitou o comentário, a música off, os letreiros e as entrevistas. Nenhuma forma de encenação faz parte dos métodos observacionais, uma vez que recusam qualquer preparação prévia ou controle

exercido sobre os materiais filmados (DARIN, 2004, p.135).

A partir do pensamento de Da-Rin, podemos notar 0 diálogo entre documentário e jornalismo presente em Bizarrus, através de elementos como cortes rápidos, depoimentos, imagens de arquivos e trilha sonora. Entretanto, devese ressaltar que as diferenças entre reportagens e documentário não os tornam superiores um ao outro, acabam em uma junção de técnicas que resultam em um instigante material audiovisual. Souza (2009, p.168) explica que:

O documentário pode recorrer à descrição jornalística, indo além dela, ou até mesmo, utilizando trechos de matérias que de uma certa maneira ajudem no desenrolar da narrativa, como visto anteriormente. Em alguns casos, a junção entre jornalismo e documentário resulta num produtivo exercício fílmico (SOUZA, 2009, p.168).

Além da presença do modo observativo, Bizarrus também revela traços do modo participativo, notadamente em função da escolha principal da realizadora, no caso, as entrevistas e os depoimentos dos personagens são prioridade no documentário, aspecto diferente dos dois documentários anteriores analisados. Assim, a atenção é voltada para quem está contando as próprias experiências. Fica aparente, em cada depoimento, a importância da técnica de ressocialização 


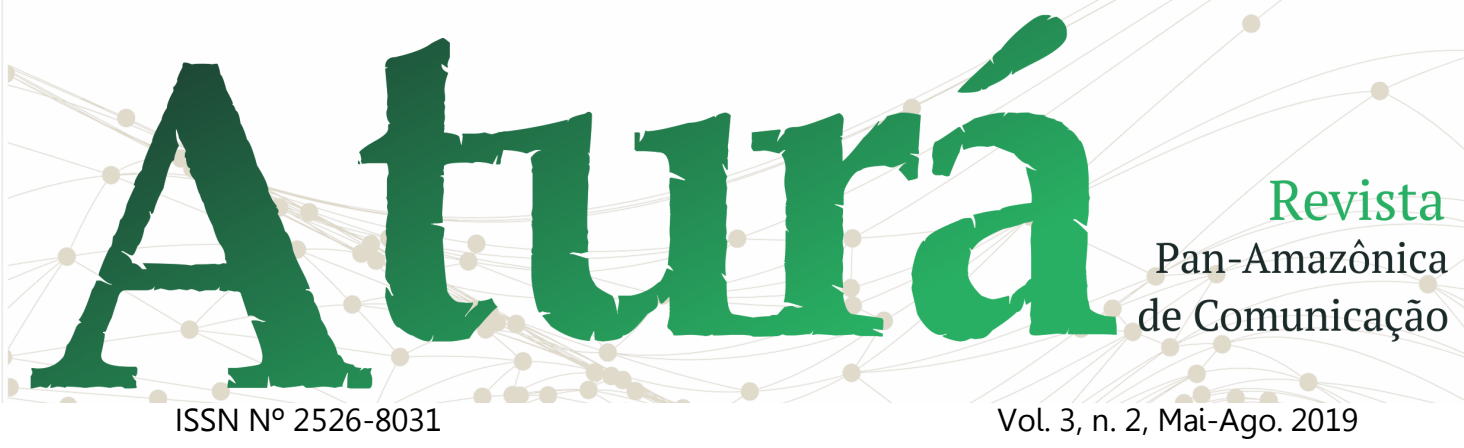

utilizada com os presos, como também aspectos de suas histórias de vida.

As cenas de massagens e terapias são no modo observacional, na forma em que o espectador não nota a presença da equipe e a atenção é voltada apenas para os atores sociais, sendo crucial para mostrar os pontos principais do discurso de cada personagem.

A proposta da realizadora Simone Norberto é mostrar todos os lados da história do projeto. Assim, ela traz outras fontes para o documentário, além dos personagens principais que são os ressocializados, como o juiz da vara de execuções penais, uma psicóloga, uma terapeuta etc.

Todos eles falam sobre como estão sendo importantes as iniciativas da Associação Cultural e de Desenvolvimento do Apenado e Egresso para novas práticas de inserção dos presos na comunidade, deixando o espectador informado de que a causa social abordada tem uma grande carga positiva.

Nessa visão, o documentário Bizarrus torna-se significativo para 0 entendimento da perspectiva temática proposta pela realizadora. A ressocialização é um tema dificilmente abordado na mídia, pouco discutido socialmente e envolto de preconceito.

A realizadora consegue 0 aprofundamento necessário nas questões abordadas, sempre com o intuito de mostrar diversos lados de cada história. A abordagem do documentário, como discutimos em nossa análise, é o ponto principal para diferenciar das reportagens jornalísticas.

Por fim, gostaríamos de pontuar algumas questões abordadas na entrevista com a realizadora e que julgamos importantes para melhor compreensão de sua produção audiovisual de não-ficção no contexto rondoniense. Questionada sobre seus procedimentos de criação e métodos de trabalho, Simone explica que sua equipe é sempre composta por poucas pessoas. O processo de criação é feito pela própria realizadora, compreendendo questões de roteiro, concepção e direção.

Ela comenta que, no caso de um documentário, ela gosta bastante de ir a campo, conhecer a história, ouvir o personagem e a comunidade etc. Já em relação à edição de seus filmes, ela fala que o processo é feito por um editor, mas que sempre trabalha acompanhado sob sua supervisão. Seu processo de imersão nos locais de cada documentário não é necessariamente longo, dependendo mais da necessidade de realização para cada caso.

Em relação às temáticas de seus documentários, ela diz que prefere, em geral, trabalhar com abordagens sociais e culturais, aspecto que, para muitos 


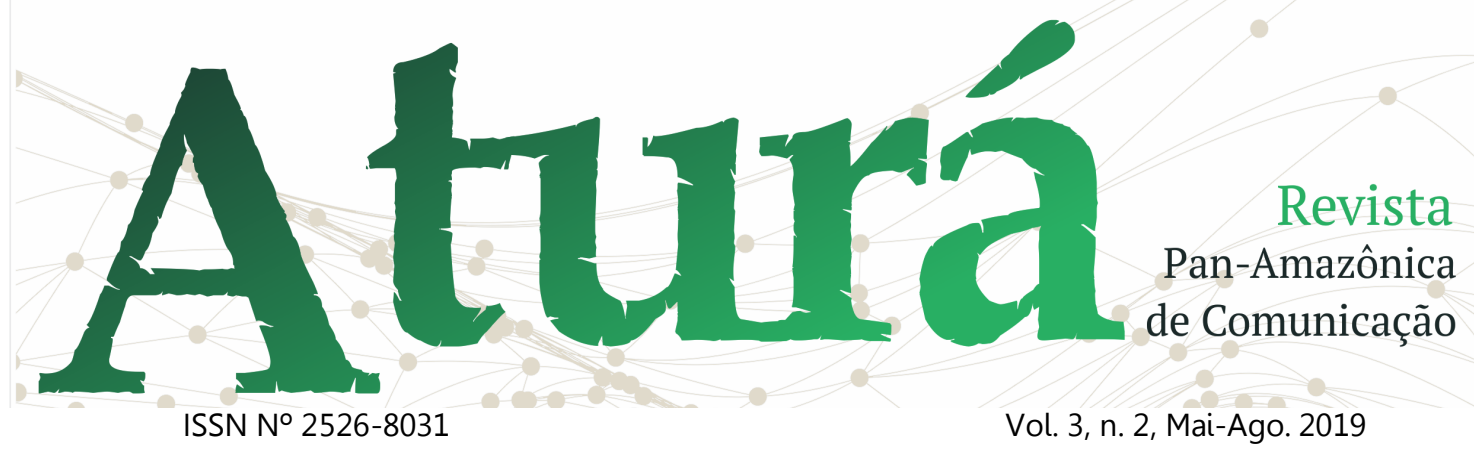

documentaristas é essencial, na perspectiva de mostrar para a sociedade um contexto que não é abordado no cotidiano dos meios de comunicação, dando mais visibilidade para causas minoritárias.

\section{Considerações finais}

Abordando temáticas regionais, culturais e sociais, a realizadora Simone Norberto consegue, por meio de seus filmes, fazer um importante registro audiovisual para Rondônia. Os documentários oferecem ao telespectador temas que não são tratados em âmbito nacional e regionalmente pouco desenvolvidos.

A análise também revelou que o estilo de seus documentários pode ser associado às características de produção do jornalismo televisivo, como o comentário em voz over e uma edição com cortes rápidos. Isso nos permite situá-la, de certa forma, na interseção entre o documentário e o telejornalismo.

Vale destacar que, segundo a própria realizadora, sua tentativa sempre foi propor um material especial a partir do que ela vivenciou produzindo uma reportagem para um telejornal. Assim, utilizando o poder de alcance que a televisão tem, ela faz um material diferente do cotidiano no formato de documentário com um enfoque mais aprofundado, crítico e político.

Para a realização de seus filmes, é importante ressaltar a importância das estruturas institucionais da Rede Amazônica de Televisão que, apesar de não incentivar diretamente suas produções audiovisuais, acabou acolhendo suas propostas, e também da Coordenadoria de Comunicação do Tribunal de Justiça, onde Simone trabalha atualmente. Destacamos, assim, a iniciativa da profissional no sentido de usar a estrutura que tinha para, na medida do possível, concretizar o processo de realização de seus filmes.

\section{Referências}

AUMONT, Jacques e MARIE, Michel. A análise do filme. Lisboa: Edições Texto \& Grafia, 2009.

DA-RIN, Silvio. Espelho partido: tradição e transformação do documentário. $4^{\mathrm{a}}$ ed. Rio de Janeiro: Azougue, 2008.

NICHOLS, Bill. Introdução ao documentário. $6^{a}$ ed. Trad. Mônica Saddy Martins. Campinas, SP: Papirus, 2016.

NORBERTO, Simone. Depoimento. [13 de junho, 2017]. Porto Velho. Entrevista concedida a Juliano José de Araújo.

NORBERTO, Simone. "Os mitos ribeirinhos nas narrativas orais da Comunidade de Nazaré/Rondônia". In: 


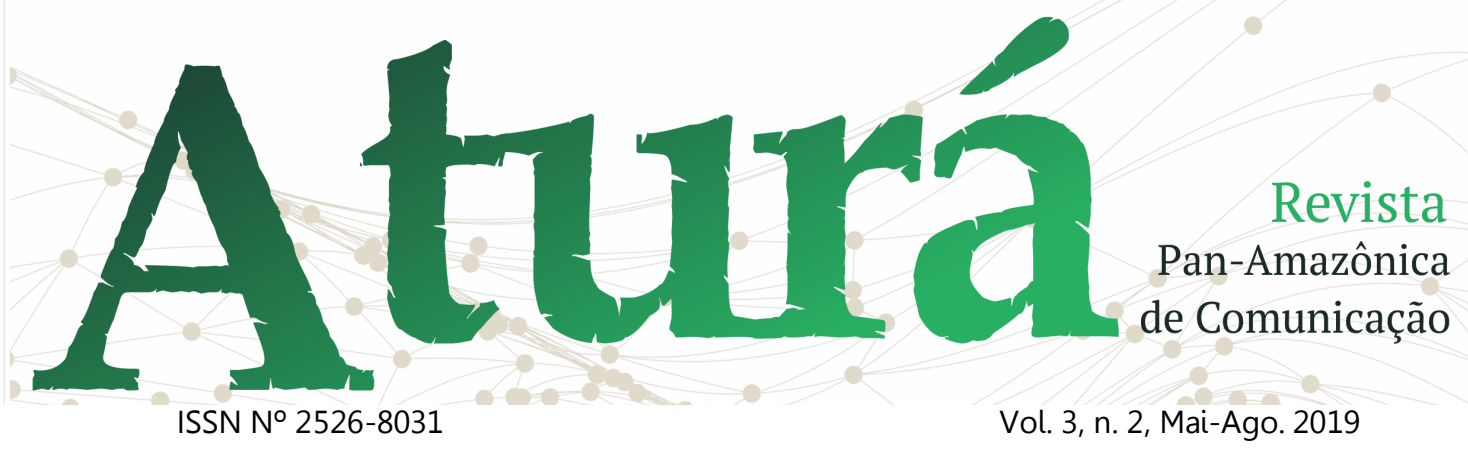

Anais Eletrônicos do XV Encontro da Associação Brasileira de Literatura Comparada. 19 a 23 de setembro de 2016. Rio de Janeiro. Disponível em http://www.abralic.org.br/anais/?ano=201 6

PENAFRIA, Manuela. "Análise de filmes: conceitos e metodologias". In: VI Congresso SOPCOM. Abril de 2009.

SOUSA, Gustavo. "Fronteiras (in)definidas: aproximações e divergências entre documentário e jornalismo". In: Doc OnLine - Revista Digital de Cinema Documentário, Covilhã (Portugal), número 06, agosto 2009.

TJRO. Bizarrus: última apresentação do ano emociona mais uma vez. Disponível em: <https://www.tjro.jus.br/noticia/faces/ jsp/noticiasview.jsp;jsessionid =ac1302213 0d705645135ff454b66ad29a2da0d41b66 1.e3irb3etc310ah4nby0?cddocumento $=1$ 60628 tpmateria $=2>$. Acesso em 15 de maio de 2018. 